\title{
Retraction Note to: Probability distribution of seasonal temperature based on GIS and management of employment information of college students
}

\author{
Li Xiang ${ }^{1}$
}

Published online: 3 November 2021

(c) Saudi Society for Geosciences 2021

Retraction Note to: Arabian Journal of Geosciences (2021) 14: 1100 https://doi.org/10.1007/s12517-021-07413-8

The Editor-in-Chief and the Publisher have retracted this article because the content of this article is nonsensical. The peer review process was not carried out in accordance with the Publisher's peer review policy. The author has not responded to correspondence regarding this retraction.

The original article can be found online at https://doi.org/10.1007/ s12517-021-07413-8.

Li Xiang

xiangli6543@163.com

1 International Business School, Zhengzhou Tourism College, Zhengzhou 451464, China 